I am grateful to Dr. B. W. Powell, consultant paediatrician, for providing access to the clinical records of both babies.

\section{References}

Galton, M. M., Smith, W. V., McElrath, H. B., and Hardy, A. V. (1954). fournal of Infectious Diseases, 95, 236.
Kallings, L. O., Ringertz, O., and Silverstolpe, L. (1966). Acta Pharmaceutica Suecica, 3, 219.

McCullough, N. B., and Eisle, C. W. (1951a). Fournal of Infectious Diseases, 88, 278.

McCullough, N. B., and Eisele, C. W. (1951b). Fournal of Infectious Diseases, $89,209,259$.

McDonagh, V. P., and Smith, H. G. (1958). Fournal of Hygeine, 56, 271.

Pharmaceutical Society (1971). Pharmaceutical fournal, 207, 400.

Smith, H. W. (1960). Fournal of Hygiene, 58, 381 .

\title{
Short-term Evaluation of Synovectomy in Haemophilia
}

\section{PIETROGRANDE， N. DIOGUARDI， P. M. MANNUCCI}

British Medical fournal, 1972, 2, 378-381

\begin{abstract}
Summary
Twenty-three operations of synovectomy (15 on the knee, 5 on the ankle, and 3 on the elbow) were carried out over a three-year period in 19 patients with severe haemophilia $A$ and $B$ who were followed for an average period of 15 months postoperatively. Short-term evaluation of the results was mainly based on the postoperative incidence of haemarthrosis and on the range of joint motion, which were compared with the preoperative findings. Synovectomy reduced, but did not abolish, the occurrence of haemarthrosis; however, after the operation bleeding episodes were usually less severe and incapacitating. Joint mobility was often reduced despite an intensive and prolonged programme of physiotherapy. Nevertheless, most of the patients were pleased with the results of the operation as they could lead a more active life because of the decreased risk of joint bleeding.

In the light of these findings we conclude that synovectomy is not the elective treatment of choice for haemophilic arthropathy. It may be indicated in a few selected cases when conservative treatment has failed to control repeated haemarthrosis and synovitis. Controlled clinical trials and long-term evaluation are needed to establish its effect on the final outcome of haemophilic arthropathy.
\end{abstract}

\section{Introduction}

The risk of haemorrhage associated with any surgical procedure has severely limited orthopaedic surgery in haemophiliacs. This is reflected in the relatively small number of orthopaedic operations carried out in the past 20 years and in the fact that most reported cases were emergencies, such as amputations and reductions of fractures. General reviews of this problem, with description of extensive personal experience, have been published by Ahlberg (1965) and Trueta (1966).

The recent increased availability of new and more potent concentrates of clotting factors, together with more favourable results with general surgical procedures, should change the pattern of orthopaedic surgery in these patients. Elective surgery, which can now be undertaken in specialized units without undue risk, offers a means of correcting established deformities and reducing disability. Moreover, synovectomy has been proposed for the prevention of arthropathy on the basis

Isntituto G. Pini, University of Milan, Italy

V. PIETROGRANDE, M.D., Professor of Orthopaedic Surgery

Institute of Medical Pathology, University of Milan, Italy

N. DIOGUARDI, M.D., Professor of Medicine

P. M. MANNUCCI, M.D., Senior Lecturer in Medicine and Physician, Haemophilia Centre of excellent results characterized by the absence of new episodes of haemarthrosis and by pronounced functional improvement in the joint (Storti et al., 1969). A consistent amelioration of the general bleeding tendency was also found, as expressed by the decrease in number and severity of the bleeding episodes in sites other than in the operated joints (Storti et al., 1969).

This paper evaluates the results of a programme for the elective surgical management of haemophilic arthropathy based on synovectomy. The purpose of the study was to observe and document the short-term effect of the operation on the occurrence of haemarthrosis and on the range of joint movement in 19 patients who were followed for an average of 15 months postoperatively.

\section{Material and Methods}

Twenty-three synovectomies (15 on the knee, 5 on the ankle, and 3 on the elbow) were carried out over a three-year period in 19 patients with severe haemophilia A or B (factor VIII or IX less than $2 \%$ ). On several occasions more than one procedure was performed at one time to take full advantage of the protection given by the replacement therapy. The patients' ages at the time of surgery ranged from 4 to 51 years (see Table).

Of the 19 patients 13 had been regularly followed at the haemophilia centre and at the orthopaedic clinic for at least 12 months before the operation, and their bleeding episodes and substitution therapy had been recorded. The remaining patients were referred from other hospitals, and hence their preoperative records were not available.

Synovectomy was the procedure of choice in patients presenting with a persistent tendency to recurrent haemorrhages in the same joint (knee, elbow, and ankle) and with local signs of synovitis (swelling, heat, and thickening of the periarticular tissues). Other criteria of selection were the absence of severe radiological changes and good preservation of joint mobility corresponding largely to grades 1 and 2 of the classification of haemophilic arthropathy proposed by De Palma and Cotler (1956). The age of the patients did not affect their selection for synovectomy. The indication for operation was established after conservative treatment (early substitution therapy or short courses of regular prophylaxis with concentrates associated with corticosteroids given either locally or parenterally) had failed to produce a consistent improvement.

Surgical Technique.-The objective of synovectomy was to remove as much as possible of the synovial membrane without interfering with the function and stability of the ligament mechanism. The knee was approached through two parapatellar incisions, the elbow with a single lateral incision, and the ankle with two incisions, one medial and the other lateral. Aprotinin (Trasylol) was injected into the joints at the end of the operation (200,000-300,000 IU).

Postoperative Treatment and Follow-up.-After wound closure the knee and ankle were immobilized with a well-padded plaster cast for 15 days. Crutch walking with a posterior splint was 
Details of Patients before and after Operation

\begin{tabular}{|c|c|c|c|c|c|c|c|c|c|c|}
\hline \multirow{2}{*}{$\begin{array}{l}\text { Case } \\
\text { No. }\end{array}$} & \multirow{2}{*}{$\begin{array}{l}\text { Deficient } \\
\text { Clotting } \\
\text { Factor }\end{array}$} & \multirow{2}{*}{$\begin{array}{c}\text { Age at } \\
\text { Operation } \\
\text { (Years) }\end{array}$} & \multirow{2}{*}{$\begin{array}{l}\text { Follow-up } \\
\text { after } \\
\text { Operation } \\
\text { (Months) }\end{array}$} & \multirow{2}{*}{$\begin{array}{l}\text { Synovectomy } \\
\text { (Side and Joint) }\end{array}$} & \multicolumn{2}{|c|}{$\begin{array}{l}\text { Bleeding Episodes } \\
\text { in Operated } \\
\text { Joint (Per Month) }\end{array}$} & \multicolumn{2}{|c|}{$\begin{array}{l}\text { Range of Joint } \\
\text { Extension and Flexion }\end{array}$} & \multirow{2}{*}{$\begin{array}{l}\text { Patient's } \\
\text { Assessment } \\
\text { of the } \\
\text { Overall } \\
\text { Results }\end{array}$} & \multirow{2}{*}{ Comments } \\
\hline & & & & & Preop. & Postop. & Preop. & $\begin{array}{c}\text { Postop. } \\
\text { (After Re- } \\
\text { habilitation) }\end{array}$ & & \\
\hline 1 & VIII $(<1 \%)$ & 20 & 31 & L. knee & N.K. & 0.3 & $180^{\circ}-90^{\circ}$ & $170^{\circ}-100^{\circ}$ & Improved & Cryoprecipitate for 6 days postop. (total dose \\
\hline 2 & VIII $(<1 \%)$ & 23 & 27 & R. knee & $2 \cdot 1$ & None & $180^{\circ}-80^{\circ}$ & $180^{\circ}-160^{\circ}$ & Worse & $\begin{array}{l}\text { Cryoprecipitate for } 6 \text { days postop. (total dose } \\
87 \mathrm{U} / \mathrm{kg} \text { ). Manipulation of joint at } 7 \text { th and }\end{array}$ \\
\hline 3 & $\mathrm{IX}(<1 \%)$ & 51 & 23 & L. knee & N.K. & None & $170^{\circ}-90^{\circ}$ & $180^{\circ}-130^{\circ}$ & Worse & $\begin{array}{l}\text { Factor IX concentrate for } 6 \text { days postop. (total } \\
\text { dose } 70 \mathrm{U} / \mathrm{kg} \text { ). Manipulation of joint at } 9 \text { th }\end{array}$ \\
\hline 4 & VIII $(<1 \%)$ & 5 & 20 & $\left\{\begin{array}{l}\text { R. knee } \\
\text { L. knee }\end{array}\right.$ & N.K. & $\left\{\begin{array}{l}0.3 \\
0.4\end{array}\right.$ & $\begin{array}{l}180^{\circ}-80^{\circ} \\
180^{\circ}-80^{\circ}\end{array}$ & $\left.\begin{array}{l}180^{\circ}-90^{\circ} \\
180^{\circ}-90^{\circ}\end{array}\right\}$ & Improved & $\begin{array}{l}\text { month postop. } \\
\text { Cryoprecipitate for } 6 \text { days postop. (total dose }\end{array}$ \\
\hline 5 & IX $(<1 \%)$ & 12 & 19 & L. knee & $2 \cdot 3$ & N.K. & $180^{\circ}-90^{\circ}$ & $180^{\circ}-90^{\circ}$ & Improved & Factor IX concentrate for 6 days postop. (total \\
\hline 6 & IX $(<1 \%)$ & 37 & 19 & L. knee & $2 \cdot 0$ & None & $180^{\circ}-165^{\circ}$ & $180^{\circ}-140^{\circ}$ & Improved & $\begin{array}{l}\text { Factor IX concentrate for } 5 \text { days postop. (total } \\
\text { dose } 51 \text { U/ } / \mathbf{k g} \text { ). Bleeding in operated joint on }\end{array}$ \\
\hline 7 & VIII $(<1 \%)$ & 7 & 19 & L. ankle & 1.8 & None & $145^{\circ}-80^{\circ}$ & $145^{\circ}-80^{\circ}$ & Improved & $\begin{array}{l}\text { oth day postop. } \\
\text { Cryoprecipitate for } 6 \text { days postop. (total dose } \\
97 \text { U } / \mathrm{kg} \text { ) }\end{array}$ \\
\hline 8 & VIII $(<1 \%)$ & 8 & 17 & L. knee & $2 \cdot 1$ & 0.3 & $150^{\circ}-95^{\circ}$ & $180^{\circ}-70^{\circ}$ & Improved & Cryoprecipitate for 6 days postop. (total dose \\
\hline 9 & VIII $(<1 \%)$ & 24 & 17 & L. elbow & $1 \cdot 6$ & $1 \cdot 8$ & $180^{\circ}-45^{\circ}$ & $135^{\circ}-50^{\circ}$ & No different & $\begin{array}{l}\text { Porcine A.H.G. for } 6 \text { days postop. (total dose } \\
116 \mathrm{U} / \mathrm{kg} \text { ). Bleeding in operated joint } 8 \text { th day }\end{array}$ \\
\hline 10 & IX $(<1 \%)$ & 43 & 15 & L. elbow & $2 \cdot 3$ & 0.2 & $160^{\circ}-80^{\circ}$ & $140^{\circ}-80^{\circ}$ & Improved & Factor IX poncentrate for 6 days postop. (total \\
\hline 11 & VIII $(<1 \%)$ & 5 & 15 & R. knee & $1 \cdot 7$ & $0 \cdot 3$ & $180^{\circ}-80^{\circ}$ & $160^{\circ}-100^{\circ}$ & No different & $\begin{array}{l}\text { Cryoprecipitate for } 6 \text { days postop. (total dose } \\
87 \text { U/kg). Bleeding in operated joint on } 7 \text { th } \\
\text { day postop. }\end{array}$ \\
\hline 12 & $\operatorname{IX}(<1 \%)$ & 29 & 10 & L. knee & N.K. & None & $170^{\circ}-95^{\circ}$ & $180^{\circ}-125^{\circ}$ & No different & $\begin{array}{l}\text { Factor IX concentrate for } 8 \text { days postop. (total } \\
\text { dose } 110 \mathrm{U} / \mathbf{k g} \text { ) }\end{array}$ \\
\hline 13 & VIII $(<1 \%)$ & 18 & 9 & R. knee & $1 \cdot 8$ & $0 \cdot 2$ & $180^{\circ}-80^{\circ}$ & $180^{\circ}-135^{\circ}$ & Improved & Porcine A.H.G. for 8 days postop. (total dose \\
\hline 14 & VIII $(<1 \%)$ & 23 & 9 & R. elbow & $1 \cdot 0$ & None & $125^{\circ}-90^{\circ}$ & $125^{\circ}-100^{\circ}$ & No different & Porcine A.H.G. for 8 days postop. (total dose \\
\hline 15 & VIII $(<2 \%)$ & 9 & 9 & R. knee & N.K. & 0.4 & $175^{\circ}-95^{\circ}$ & $180^{\circ}-145^{\circ}$ & No different & Cryoprecipitate for 8 days postop. (total dose \\
\hline 16 & VIII $(<1 \%)$ & 12 & 9 & L. knee & $2 \cdot 1$ & $0 \cdot 2$ & $170^{\circ}-110^{\circ}$ & $180^{\circ}-100^{\circ}$ & Improved & $\begin{array}{l}\text { Cryoprecipitate for } 8 \text { days postop. (total dose } \\
182 \mathrm{U} / \mathrm{kg} \text { ) }\end{array}$ \\
\hline 17 & VIII $(<1 \%)$ & 5 & 8 & $\left\{\begin{array}{l}\text { L. knee } \\
\text { R. ankle }\end{array}\right.$ & N.K. & $\left\{\begin{array}{c}0.4 \\
\text { None }\end{array}\right.$ & $\begin{array}{l}180^{\circ}-90^{\circ} \\
145^{\circ}-80^{\circ}\end{array}$ & $\left.\begin{array}{l}180^{\circ}-100^{\circ} \\
145^{\circ}-80^{\circ}\end{array}\right\}$ & Improved & $\begin{array}{l}\text { Cryoprecipitate for } 9 \text { days postop. (total dose } \\
149 \mathrm{U} / \mathrm{kg} \text { ) }\end{array}$ \\
\hline 18 & VIII $(<1 \%)$ & 4 & 6 & $\begin{array}{l}\text { R. ankle } \\
\text { L. ankle }\end{array}$ & $1 \cdot 1$ & None & $\begin{array}{l}145^{\circ}-80^{\circ} \\
145^{\circ}-80^{\circ}\end{array}$ & $\left.\begin{array}{l}140^{\circ}-90^{\circ} \\
145^{\circ}-80^{\circ}\end{array}\right\}$ & Improved & $\begin{array}{l}\text { Cryoprecipitate for } 9 \text { days postop. (total dose } \\
181 \mathrm{U} / \mathrm{kg})\end{array}$ \\
\hline 19 & VIII $(<1 \%)$ & 43 & 6 & $\left\{\begin{array}{l}\text { L. knee } \\
\text { R. ankle }\end{array}\right.$ & $1 \cdot 8$ & None & $\begin{array}{l}180^{\circ}-90^{\circ} \\
140^{\circ}-100^{\circ}\end{array}$ & $\left.\begin{array}{l}180^{\circ}-110^{\circ} \\
140^{\circ}-90^{\circ}\end{array}\right\}$ & No different & $\begin{array}{l}\text { Cryoprecipitate for } 7 \text { days postop. (total dose } \\
138 \mathrm{U} / \mathrm{kg} \text { ) }\end{array}$ \\
\hline
\end{tabular}

N.K. = Not known.

allowed one week later, and full-weight bearing was started 30 days after the operation. The elbow was held in a well-padded plaster posterior splint in $90^{\circ}$ of flexion and in neutral rotation. All patients were instructed to start isotonic muscular contractions of the limbs on the day after the operation. After removal of the cast intensive physical therapy for recovery of joint mobility started and continued for two to six months depending on the clinical course of the individual case. Manipulation of the operated joint was performed in two cases when motion was severely limited despite an appropriate physiotherapy programme. Postoperatively all patients were regularly followed at the haemophilia centre and at the orthopaedic clinic for an average of 15 (range 6-31) months.

Replacement Therapy.-A detailed investigation of haemostasis, including assay of factors VIII and IX and a test for the presence of circulating anticoagulants, was carried out before operation. Factor VIII and IX assays were repeated during the postoperative course before and after each dose of replacement therapy. All operations were carried out under cover of clottingfactor concentrates. As a general rule blood-bank or commercial lyophilized cryoprecipitate was used for the operations carried out in patients with haemophilia A; porcine antihaemophilic globulin (A.H.G.) was used in a few cases. Patients with haemophilia B were treated with a new factor IX concentrate (Bebulin-Immuno, Vienna) made by absorption of the supernatant of cryoprecipitation on DEAE Sephadex. The principle of the management of the substitution therapy was to administer a large dose of concentrate immediately before operation, aiming to attain a preoperative level of factor VIII or IX of at least $50 \%$. Successive smaller doses were given for five or six days postoperatively, spaced so that at any time the levels of factor VIII or IX were not lower than $5 \%$. Later the period for substitution therapy was extended to eight to nine days for reasons discussed below. Antifibrinolytic drugs (aminocaproic acid $0.3 \mathrm{~g} / \mathrm{kg}$ or tranexamic acid $0.05 \mathrm{~g} / \mathrm{kg}$ of body weight) were administered daily to all patients during the postoperative period for at least 15 days.

\section{Results}

The evaluation of the results was based on the following criteria: range of movement, recurrence of haemarthrosis, and external appearance of the operated joint. Moreover, the patients or their parents were asked to assess the overall results of the operation and to rate them as "improved," "worse," or "no different." The radiological picture of the joints was not included among the criteria of evaluation for the relatively short period of the follow-up.

Details of the patients before operation, the surgical procedures carried out, the dosage and duration of the substitution therapy, and the complications are summarized in the Table.

Recurrence of Haemarthrosis.-The number of bleeding episodes occurring in the same joint before and after the operation and severe enough to require substitution therapy are shown in the Table. In most patients haemarthrosis was reduced but not abolished by synovectomy. We had the impression, however, that the episodes were generally less painful, severe, and incapacitating. There was no evidence to suggest that the general bleeding tendency had been favourably influenced by operation.

Range of Movement.-The recovery of joint mobility after operation required a prolonged period of physical therapy which could, however, be carried out more actively and intensively than before operation owing to the decreased risk of joint bleeding. In many patients even after prolonged physiotherapy the original joint mobility was not regained, and in some there was persistent and severe impairment despite postoperative manipulation under general anaesthesia. The most favourable results were obtained in the younger patients presenting before 
he operation with a normal range of mobility and with fewer radiological alterations of the affected joint.

Appearance of foints.- All operated joints showed improvement in appearance, with a decrease in swelling and heat. Pain, which was present in six joints before surgery, was completely relieved in every instance; however, two joints which were initially free of pain became tender when used.

Patient's Evaluation.-Despite some reduction of joint mobility 11 patients were pleased with the results of the operation as they could lead a more active life, which previously had been severely limited by the frequency of bleeding episodes and by the delay before recovery of limb function after each attack. Six noted no real improvement although their condition had not worsened. Two patients expressed dissatisfaction with the operation owing to the unexpected limitation of limb function.

Complications. - In three patients (Cases 6, 9, and 11) bleeding into the operated joint occurred on the 6th, 8th, and 7th postoperative days respectively (see Table). In these cases substitution therapy had already been stopped but antifibrinolytic drugs were still being administered. These episodes of postoperative bleeding were never dangerous, did not require blood transfusions, and did not appear to affect the outcome of the operation. They were related to the short course of substitution therapy, which was subsequently extended to eight or nine days.

\section{Discussion}

In centres where necessary haematological, surgical, and transfusion facilities are available postoperative bleeding can be successfully avoided by the co-operation of the teams and the proper use of modern clotting-factor concentrates. Storti et al. (1969) proposed with their operations of synovectomy a scheme based on large doses of antifibrinolytic drugs given (locally as well as parenterally) in association with replacement therapy. This led to successful operations without any bleeding complications with the use of small doses of fresh-frozen plasma (10 $\mathrm{ml} / \mathrm{kg}$ ) given on the day of operation and repeated daily for three or four days thereafter. These findings were not confirmed in our series, where postoperative bleeding occurred in three patients despite the use of concentrates given in larger doses and for a longer period than was given by Storti et al. (1969). The haemorrhages were never dangerous and did not adversely influence the final outcome of the operations; however, we feel that although the use of antifibrinolytic drugs may undoubtedly allow a reduction of the total dose of concentrates it is not possible to reduce the dose to too small an amount if success is regarded as a postoperative course similar to that in subjects with normal haemostasis.

The main goal for the use of synovectomy in our programme of elective orthopaedic surgery in haemophiliacs was to stop the recurrence of haemorrhages in the joint through the removal of the altered synovial membrane. This was not achieved in most patients, although the bleeding episodes were usually less frequent and less incapacitating than before the operation. In the patient's estimate of satisfactory improvement the frequency of haemarthrosis and its accompanying pain and functional disability were the chief determining factors. It was therefore not surprising to find that despite the impairment of joint mobility most of the patients were pleased by the operation, which often resulted in an improved pattern of life through the reduction of frequency and severity of haemarthrosis.

The failure of synovectomy to abolish the recurrence of bleeding into the operated joints is possibly related to the fact that the synovial membrane is only partially removed, despite the use in the present series of a surgical technique which allowed a more complete removal than that used by Storti $e t$ al. (1969). Possibly for the same reason, the results of synovectomy of the elbow, where the synovial membrane is less easily accessible, were less satisfactory than those of the knee and ankle. Moreover, it is well known that synovial regeneration occurs soon after removal, although the newly formed subsynovial tissue contains fewer blood vessels and hence is less apt to bleed (Key, 1925; Woolcott, 1927; Mitchell and Cruess, 1967).

Recovery of the range of movement present before the operation was a formidable problem after synovectomy. Mobility was often reduced despite intensive and prolonged physiotherapy and, in a few cases, manipulation of the joint. As suggested for synovectomy in rheumatoid arthritis, more favourable results might be obtained by earlier mobilization, which should, however, be carried out under intensive cover with clotting-factor concentrates.

Similar or less favourable results have been obtained with synovectomy in other centres where the operation has been attempted in a few cases (J. P. Allain, personal communication, 1971; G. I. C. Ingram, personal communication, 1971; C. Rizza, personal communication, 1971). Therefore these cases and the short-term results of the present series suggest that synovectomy is not, as suggested by Storti et al. (1969), the elective treatment of choice for haemophilic arthropathy and that the indication for the operation is likely to be confined to a few selected cases where conservative treatment has failed to control repeated haemarthrosis and synovitis. Moreover, earlier and more extensive synovectomy might be considered in patients who live far from a haemophilia centre or in countries where modern treatment is not readily available.

The outcome of arthropathy, which is inevitable in these patients, could possibly be favourably influenced by synovectomy if carried out at an early stage. In these cases, however, an alternative to surgical synovectomy might be intra-articular injections of radioactive gold (Ahlberg, 1971) and osmic acid (Risse et al., 1971), which would eliminate the need for the surgical procedure. A firm answer to the question of the overall benefits from these procedures, as well as more detailed information about the indications and selection of cases, is needed before encouraging further experience in this field. Moreover, the long-term effect of synovectomy on the radiological changes of the joints remains to be seen, and was not evaluated in the present series owing to the relatively short period of observation. Since the effect of any form of treatment on haemophilia needs controlled evaluation a multicentre trial should be organized to assess the long-term results and the relative advantages of the various procedures.

\section{Addendum}

Since acceptance of this paper, Storti and Ascari (1972) have re-evaluated their results from synovectomy carried out in 47 patients who were followed up for up to six years. Haemarthrosis was abolished in $76 \%$ of the operated joints; slight to moderate bleeding episodes, not requiring the substitution therapy, were observed in the remaining cases. Joint function was good in the majority of patients, whereas it was impaired in those presenting more pronounced radiological alterations of the joints before the operation. Replacement therapy was administered for five to six days postoperatively in association with antifibrinolytic drugs. They concluded that the main goal of synovectomy is to stop the recurrence of haemarthrosis in the operated joint, and that the operation might be indicated in the patients with at least three episodes of haemarthrosis occurring in the same joint within six to eight months.

We would like to thank Dr. G. I. C. Ingram and Mr. W. $M$. Keynes for helpful suggestions and advice during the preparation of the manuscript. This work was suppo:ted in part by a grant from the Fondazione Angelo Bianchi Bonomi.

Requests for reprints should be addressed to Dr. P. M. Mannucci, via Pace 15, 20122 Milano, Italy. 


\section{References}

Ahlberg, A. (1965). Acta Orthopaedica Scandinavica, Suppl. No. 77. Ahlberg, A. (1971). 7th Congress of the World Federation of Haemophilia, Teheran, abstracts, p. 84 .

De Palma, A. F., and Cotler, J. M. (1956). Clinical Orthopaedics, 8, 163.

Key, J. A. (1925). Fournal of Bone and Foint Surgery, 7, 793.

Mitchell, N. S., and Cruess, R. L. (1967). Canadian fournal of Surgery, 10, 234.
Risse, J. C., Menkes, C., Allain, J. P., and Witvoet, J. (1971). 7th Congress of the World Federation of Haemophilia, Teheran, abstracts, p. 85. Storti, E., and Ascari, E. (1972). International Haemophilia Meeting, Rome, abstracts, p. 111 .

Storti, E., Traldi, A., Tosatti, E., and Davoli, P. G. (1969). Acta Haematologica, 41, 193

Trueta, J. (1966). In Treatment of Haemophilia and Other Coagulation Disorders, ed. R. Biggs and R. G. MacFarlane Oxford, Blackwell Scientific.

Woolcott, W. P. (1927). Fournal of Bone and foint Surgery, 9, 67.

\title{
Technique to Improve the Rate of Healing of Incised Abscesses
}

\author{
IAN C. RITCHIE
}

British Medical fournal, 1972, 2, 381-383

\section{Summary}

In a comparative investigation incised skin abscesses were treated by either introducing sterile fusidic acid gel into the cavity on one occasion only or applying daily superficial dressings impregnated with sodium fusidate ointment. In comparison with the dressing group, the intracavity use of fusidic acid gel reduced the mean healing time of incised abscesses by approximately onehalf. When abscesses were analysed according to site and size, the reduction in mean healing time was equally striking. No hypersentisivity or irritation to fusidic acid or its sodium salt applied by either method was observed.

The procedure of introducing fusidic acid gel into an incised abscess cavity is a promising alternative to superficial antibiotic dressings or wicks in the treatment of incised abscesses.

\section{Introduction}

It is customary in the casualty department of the Public Dispensary and Hospital, Leeds, to treat soft-tissue abscesses by incision and drainage under antibiotic cover. Both systemic and topical antibiotics have been given on the assumption that even careful curettage may fail to evacuate isolated pockets of infection, and these must be eradicated before healing can take place.

However, while systemic antibiotics are indicated when there is evidence of lymphangitis, lymphadenitis, and fever, recent investigations cast doubt on their value in localized infections. Rutherford et al. (1970) failed to show any significant difference in the mean healing times of localized skin infections treated by surgery with a course of oral cloxacillin compared with a group treated by surgery alone. They therefore concluded that cloxacillin was unable to reduce healing times of septic lesions by an amount likely to be of clinical value in treating groups of localized skin infections. Price et al. (1968) showed no difference in efficacy between penicillin $\mathrm{V}$, phenethicillin, and lincomycin, despite the observation that half the staphylococci isolated were resistant to penicillin. They suggested two possible explanations: (1) the organisms concerned were only weak producers of penicillinase and therefore had little inhibitory effect on penicillin, and (2) the reason for the equivocal results may be that

Public Dispensary and Hospital, Leeds

IAN C. RITCHIE, M.B., CH.B., late Senior Casualty Officer systemic antibiotics do not materially affect the natural course o superficial staphylococcal infections.

Topical antibiotic therapy has not found particular favour as an alternative treatment, partly because of the complication of skin sensitization. Among the most widely used topical antibiotics are neomycin and framycetin, which are particularly prone to this disadvantage. Hjorth and Thomsen (1967) reported that as many as $10 \%$ of all patients with dermatitis seen during 1964 at the Finsen Institute had an allergic contact sensitivity to these substances.

Another practical problem is that of ensuring intimate contact between local antibiotic and infecting organisms. If an antibiotic dressing is merely applied superficially over an incised abscess it is difficult for it to reach the crevices of a large abscess cavity. The use of antibiotic-impregnated wicks is a possible solution but these may delay healing and their removal causes great pain.

It was decided to investigate the value of injecting an antibiotic deep into the abscess cavity. Previous experience had shown that topical sodium fusidate was clinically effective and caused extremely few adverse reactions. A suitable gel base was developed which was sufficiently viscous to maintain prolonged contact with the lesion. An investigation was designed to compare the healing times of incised abscesses treated either by injecting the fusidic acid gel into the cavity, or by applying a superficial dressing impregnated with sodium fusidate ointment as control.

\section{Method}

All abscesses were incised and carefully curetted. On Mondays, Wednesdays, and Fridays the cavities were injected with fusidic acid gel from a sterile, disposable, single-dose injector. This had an elongated, flexible nozzle allowing application deep into the abscess cavity. A dry dressing was then applied. On Tuesdays, Thursdays, and at weekends the abscesses were incised, curetted, and treated simply with a superficial dressing impregnated with sodium fusidate ointment. All patients were asked to return daily. In those treated with fusidic acid gel the dry dressing was replaced; no further injection of fusidic acid gel was made. In the other cases the sodium fusidate ointment dressing was replaced at each attendance. Healing time was measured from the date of incision to the formation of a dry scab.

Some patients had already received systemic antibiotics from their own doctors (mainly an oral penicillin or tetracycline). Others were given short courses of antibiotics by us when there was evidence of infection spread (mainly injections of procaine penicillin). Systemic antibiotics were given to $54.2 \%$ of patients treated with fusidic acid gel and to $46 \cdot 6 \%$ of patients treated with 